Research Article

\title{
The Pressure Control of High-Pressure Tubing Based on Difference Equation
}

\author{
Yang Zhang $(\mathbb{D}$, Rongjun Li $\mathbb{D}$, and Linhai Zou $(\mathbb{D}$ \\ School of Electric Power Engineering, South China University of Technology, Guangzhou 510640, China \\ Correspondence should be addressed to Yang Zhang; 1300802724@qq.com
}

Received 2 March 2020; Revised 21 April 2020; Accepted 27 April 2020; Published 15 May 2020

Academic Editor: Marco Pizzarelli

Copyright (C) 2020 Yang Zhang et al. This is an open access article distributed under the Creative Commons Attribution License, which permits unrestricted use, distribution, and reproduction in any medium, provided the original work is properly cited.

\begin{abstract}
The situation where fuel enters and exits the high-pressure tubing is one of the important factors that affect the working efficiency of the engine. Based on the simplified high-pressure tubing model, this paper studies the control problems of high-pressure tubing injection and fuel supply under certain circumstances. According to the idea of the difference equation, the paper obtains the opening time of the one-way valve when the pressure value of the high-pressure tubing is kept constant or rises to a specific value by enumerating the opening time of the one-way valve. By establishing the physical model of the high-pressure tubing and the fuel injection nozzle, and then using the enumeration method, the angular velocity of the high-pressure oil pump cam when the pressure of the high-pressure fuel pipe is kept constant can be obtained. Under the more complicated injector model, the control method of the injector is solved by the double enumeration method. The results show that the above model can quickly calculate the optimal working time of the high-pressure fuel pump and needle valve when the accuracy meets the requirements.
\end{abstract}

\section{Introduction}

The diesel engine is one of the most widely used machinery in the world. It plays an important role in industry, national defense, and transportation. The fuel injection system is the core component of the diesel engine and is one of the important issues in diesel engine design and development. High-pressure fuel entering and ejecting tubing is the basis of the work of fuel engines. Fuel into and out of the working process of the intermittent will lead to the change of the pressure in the high-pressure tubing. The deviation of fuel flow affects the working efficiency of the engine, which affects the working efficiency of the engine. For the highpressure fuel pump, in the actual working process, the fuel of the high-pressure fuel pipe comes from the outlet of the plunger chamber of the high-pressure fuel pump. In the high-pressure fuel pump, the cam drives the plunger to move up and down. When the plunger moves up, the fuel in the plunger chamber is compressed. When the plunger moves to the top dead center, there is a residual volume in the plunger chamber. When the plunger moves to the bottom stop point, the low-pressure fuel will fill the plunger chamber (including residual volume). The injection of the high-pressure tubing is controlled by the needle valve of the nozzle. When the lift of the needle valve is 0 , the needle valve will close. When the lift of the needle valve is greater than 0 , the needle valve is opened and the fuel flows to the jet hole. The reasonable control of high-pressure fuel pipe can effectively improve the energy efficiency, which has the application prospect in the world advocating energy conservation.

In many early studies, the study and measurement of the structure parameters of the high-pressure tubing and the injection needle valve solved the problems of the injection law and characteristics but could not reflect the influence of the pressure change of the high-pressure tubing on the injection. Lee et al. proposed that the elastic modulus changes nonlinearly with pressure and used the nonlinear model to predict injection timing and peak line pressure [1]. $\mathrm{H}$. Seungwoo et al. proposed a common-rail pressure controller based on the pressure control valve (PCV) control algorithm and metering unit (MeUn) control algorithm [2]. He.J. et al. developed a high-pressure common rail fuel injection control system controlled by computer and driven 
by ECU [3]. J. Ling et al. proposed a model-based rail pressure controller (RPC) in the HPCR fuel injection system for diesel engines based on the static feedforward control algorithm and the dynamic feedforward control algorithm [4]. Their research on high-pressure common-rail systems, which control and regulate the stability and common-rail pressure, effectively predicted the amount of fuel injected into the system. But they all neglected to control the pressure inside the high-pressure tubing and did not consider the amount of fuel that would be ejected from the inside of the tubing. In order to deal with the HPCR FIS plant parameter variations due to different operating conditions, A. di Gaeta et al. proposed integrating an integrator-augmented slidingmode control with gain scheduling and feedforward term [5]. In the work of P. Lino, a control-oriented model and a nonlinear control design for a common-rail injection system are developed [6]. Both methods reflect the hydrodynamic phenomena of the FIS through physical equations. However, both of them have limited access to online calibration due to design complexity.

In our work, three physical models are established from simple to difficult analysis of the pressure control problem of high-pressure tubing. According to the different requirements, we analyze the principle of the high-pressure fuel pump, injection nozzle, cam, one-way valve working principle, and their impact on the pressure, in order to obtain the best control scheme. The results show that the above model can quickly calculate the optimal working time of the highpressure fuel pump and needle valve when the accuracy meets the requirements.

\section{System Principle for the Pressure Control of High-Pressure Tubing}

\subsection{Establishment and Solution of the First Model}

2.1.1. The Setting of Initial Condition for Simple High-Pressure Tubing. As is shown in Figure 1, we establish the simplest model and assume that each component will not deform and there is no leakage problem during the operation of the high-pressure fuel pump. There are no bubbles in the high-pressure fuel pipe, injection nozzle, and high-pressure fuel pump.

In this model, the fuel enters the high-pressure pipe through A and the fuel supply time is controlled by the oneway valve switch. The fuel injector works 10 times per second. After the one-way valve's opening, the fuel injector will be closed for $10 \mathrm{~ms}$. During each operation, the fuel injection time is $2.4 \mathrm{~ms}$, and the fuel injection rate from nozzle B is shown in Figure 2. The pressure provided by the high-pressure fuel pump at inlet $\mathrm{A}$ is $160 \mathrm{MPa}$, and the initial pressure in the high-pressure fuel pipe is $100 \mathrm{MPa}$. We will study how to set the opening time of the one-way valve to keep the pressure of the high-pressure tubing at $100 \mathrm{MPa}$ and adjust the opening time of the one-way valve to make the pressure of the high-pressure tubing go from $100 \mathrm{MPa}$ to $150 \mathrm{MPa}$ through different time periods.

In the high-pressure tubing system, the entry and ejection of fuel are carried out according to the

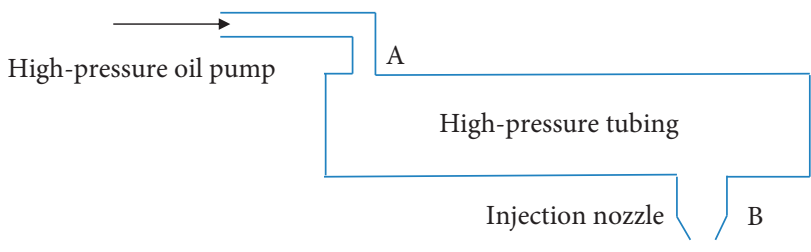

Figure 1: The schematic diagram of the first model.

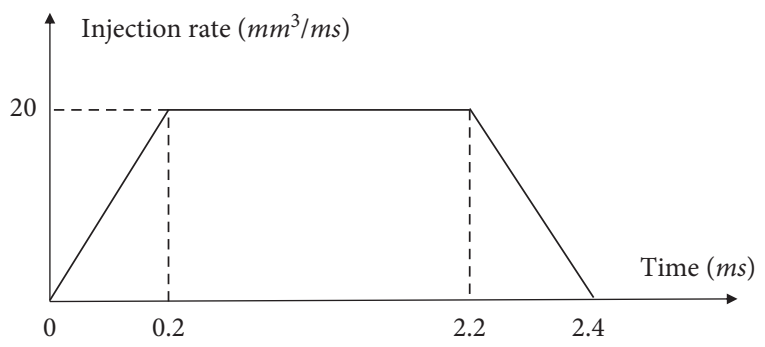

Figure 2: Diagram of injection rate and time.

corresponding law. Under the control of the one-way valve switch, there is a time interval between the last entry of fuel and the next entry of fuel, and the fuel intake within the time interval is 0 . The fuel injection pattern is similar. Therefore, it is not suitable to use common linear expressions to effectively describe the law of fuel inlet and fuel outlet in highpressure tubing. In this case, for the convenience of research, we discretize the time, so as to better analyze the influence of fuel inlet and fuel outlet on the pressure in high-pressure tubing.

The pressure in the high-pressure tubing varies with time, and the change of some parameters of the tubing at one time will affect the pressure calculation of the high-pressure tubing at the next time. We calculate the pressure change of the high-pressure tubing by establishing the difference equation due to the discretization of the time.

Under the condition given by the difference equation of pressure and time relationship of high-pressure tubing, we can use the enumeration method to start the one-way valve opening time from 0 , traverse it with $0.01 \mathrm{~ms}$ as step size, and substitute it into the corresponding difference equation to calculate the pressure change of high-pressure tubing. The enumeration method is to use the computer operation speed and the high accuracy of the characteristics, to solve the problem of all possible circumstances, not to miss the test, from which to find the answer to meet the requirements. Enumeration method sacrifices time for comprehensiveness as discussed elsewhere [7].

\subsubsection{Establishment of the First Model}

(1) Derivation of Elastic Modulus Formula. The elastic modulus of liquid is the main factor that affects the analysis of the hydraulic system as discussed in [8]. The elastic modulus data with the pressure changing from 0 to approximately $200 \mathrm{MPa}$ whose changing length is $0.5 \mathrm{MPa}$ are given in the research data. Therefore, regression analysis can be conducted to obtain the linear relationship between the 
elastic modulus and fuel pressure, providing more comprehensive data for the following research. Since the fuel pressure is between 100 and $160 \mathrm{MPa}$, in order to obtain a better linear relation of fitting degree, we conduct regression analysis in SPSS according to the elastic modulus of $90 \sim 170 \mathrm{MPa}$ in the research data. The relation between elastic modulus and fuel pressure is as follows:

$$
E=0.037 P^{2}+0.736 P+1731.344 .
$$

In the formula, $\mathrm{E}$ is the elastic modulus, and $\mathrm{P}$ is the fuel pressure.

(2) Derivation of Fuel Density Formula. The pressure change of fuel is proportional to the change of density as discussed in [9], so we can get

$$
\frac{\mathrm{d} P}{E}=\frac{\mathrm{d} \rho}{\rho} .
$$

Substitute formula (1) into formula (2) to obtain

$$
\frac{\mathrm{d} P}{0.037 P^{2}+0.736 P+1731.344}=\frac{\mathrm{d} \rho}{\rho} .
$$

Take the antiderivative of both sides of this equation and substitute $(\rho, \mathrm{P})=(0.85,100)$ into the equation to get

$$
\ln \rho=\frac{250}{\sqrt{3995269}} \tan ^{-1}\left(\frac{37 P+368}{4 \sqrt{3995269}}\right)-0.2213867 .
$$

In the formula, $\rho$ is fuel density and $P$ is fuel pressure.

(3) Calculation of Fuel Injection Amount in High-Pressure Tubing. According to the given data, the working cycle of the fuel injector is $100 \mathrm{~ms}$, and there is only $2.4 \mathrm{~ms}$ for fuel injector to work in the state of fuel injection. When the fuel injector works, the fuel injection rate varies with the opening time of the valve.

According to Figure 2, the piecewise function of fuel injection rate and time when the injector works is as follows:

$$
v=\left\{\begin{array}{l}
100 t, \quad 0 \leq t<0.2, \\
20, \quad 0.2 \leq t<2.2, \\
240-100 t, \quad 2.2 \leq t \leq 2.4 .
\end{array}\right.
$$

After integration, the relationship between fuel injection amount and time is as follows:

$$
s=\left\{\begin{array}{l}
50 t^{2}, \quad 0 \leq t<0.2 \\
20 t-2, \quad 0.2 \leq t<2.2, \\
-50 t^{2}+240 t-244, \quad 2.2 \leq t \leq 2.4
\end{array}\right.
$$

In equations (5) and (6), $v$ is the fuel injection rate of the injector, $s$ is the fuel injection amount of the fuel injector, and $t$ is the length of the opening time of the injector.

(4) Establishment of the Difference Equation. In order to make the result as accurate as possible and improve the
TABLE 1: Calculation of the required parameter values.

\begin{tabular}{lccc}
\hline Parameter & $\begin{array}{c}\text { The } \\
\text { numerical }\end{array}$ & Parameter & $\begin{array}{c}\text { The } \\
\text { numerical }\end{array}$ \\
\hline $\begin{array}{l}\rho_{160}(\text { fuel density at } \\
160 \mathrm{MPa})\end{array}$ & 0.87107 & $\begin{array}{c}\mathrm{C} \text { (flow } \\
\text { coefficient) }\end{array}$ & 0.85 \\
$\begin{array}{l}\mathrm{A} \text { (one-way valve } \\
\text { outlet area) }\end{array}$ & $0.49 \pi$ & $\begin{array}{c}\text { V (high-pressure } \\
\text { tubing volume) }\end{array}$ & $12500 \pi$ \\
$\begin{array}{l}T_{2} \text { ( one-way valve } \\
\text { switching cycle ) }\end{array}$ & $10+t_{s}$ & $\begin{array}{c}T_{1} \text { (nozzle } \\
\text { switching cycle) }\end{array}$ & 100 \\
\hline
\end{tabular}

efficiency, we set up the difference equation whose step size $\left(\Delta \mathrm{t}_{\mathrm{i}}\right)$ is $0.01 \mathrm{~ms}$. Before establishing the difference equation, the values of some relevant parameters need to be calculated. The results are shown in Table 1.

Take the calculation of step $(n)$ as an example to write the difference equation. The specific steps are as follows:

(1) Judge the working state of the one-way valve and the nozzle according to the total running time and get the change of fuel volume in the high-pressure tubing after a difference step:

$$
\Delta V_{1}=\left\{\begin{array}{l}
50\left[t_{1}^{2}-\left(t_{1}-\Delta t_{i}\right)^{2}\right], \quad 0 \leq t_{1} \leq 0.2, \\
20 \cdot \Delta t_{i}, \quad 0.2<t_{1} \leq 2.2, \\
-240 \cdot \Delta t_{i}+50\left[t_{1}^{2}-\left(t_{1}-\Delta t_{i}\right)^{2}\right], \quad 2.2<t_{1} \leq 2.4 \\
0, \quad t_{1}>2.4
\end{array}\right.
$$

$\Delta V_{2}=\left\{\begin{array}{l}Q_{n-1} \cdot \Delta t_{i}, \quad t_{2} \leq t_{s}, \\ 0, \quad t_{2}>t_{s} .\end{array}\right.$

In formulas (7) and (8), $t_{1}$ is the remainder obtained by dividing the running time $\left(t_{n}\right)$ by a switching period of the nozzle $\left(T_{1}\right) ; t_{2}$ is the remainder obtained by dividing the running time $\left(t_{n}\right)$ by one switching cycle of the one-way valve $\left(T_{2}\right) ; t_{s}$ is the time for the one-way valve to open at one time; $\Delta t_{i}$ is the step size calculated by difference; $Q_{n-1}$ is the one-way valve's flow calculated in the previous step.

(2) According to the above steps, the variation of fuel quality in the high-pressure fuel pipe $\left(\Delta m_{n}\right)$ can be calculated. Then, the variation of fuel density in the high-pressure fuel pipe $\left(\Delta \rho_{n}\right)$ can be got. In addition, the variation of fuel pressure in the high-pressure fuel pipe $\left(\Delta P_{n}\right)$ can be obtained. The formulas are as follows:

$$
\begin{aligned}
\Delta m_{n} & =\Delta V_{2} \cdot \rho_{160}-\Delta V_{1} \cdot \rho_{n-1}, \\
\Delta \rho_{n} & =\frac{\Delta m_{n}}{V},
\end{aligned}
$$




$$
\Delta P_{n}=\frac{0.037 P_{n-1}^{2}+0.736 P_{n-1}+1731.344}{\rho_{n-1}} \cdot \Delta \rho_{n} .
$$

In equations (9) (11), $P_{n-1}$ and $\rho_{n-1}$ are, respectively, the fuel pressure and density of the high-pressure tubing calculated in the previous step. $V$ is the volume of the high-pressure fuel pipe; $\rho_{160}$ is the fuel density at $160 \mathrm{MPa}$.

(3) According to the calculation of step (2), the changes in each parameter of the high-pressure tubing can update the fuel density $\left(\rho_{n}\right)$, pressure $\left(P_{n}\right)$, running time $\left(t_{n+1}\right)$, and one-way valve fuel flow $\left(Q_{n}\right)$ in the high-pressure tubing. The formulas are as follows:

$$
\left\{\begin{array}{l}
\rho_{n}=\rho_{n-1}+\Delta \rho_{n}, \\
P_{n}=P_{n-1}+\Delta P_{n}, \\
t_{n+1}=t_{n}+\Delta t_{i}, \\
Q_{n}=C A \sqrt{\frac{2\left(160-P_{n}\right)}{\rho_{160}}}
\end{array}\right.
$$

where $C$ is the flow coefficient and $A$ is the outlet area of the one-way valve.

(4) Substitute the values of $\rho_{n}, P_{n}, Q_{n}$, and $t_{n+1}$ into $\rho_{n-1}, P_{n-1}, Q_{n-1}$, and $t_{n}$, and return to step (1) for the next calculation until the running time $\left(\mathrm{t}_{\mathrm{n}}\right)$ is $1 \mathrm{~s}$.

(5) Application of Enumeration in Solving Difference Equations. The value range of the opening time of the oneway valve is $0 \sim 2 \mathrm{~ms}$. We take $\Delta \mathrm{t}_{\mathrm{s}}=0.01 \mathrm{~ms}$ as the traversal step, then get the fuel pressure change under each step by solving the difference equation, and filter the target time according to certain indexes required by the model.

2.1.3. Solution of the First Model. Before the difference operation, the initial value of some physical parameters must be known, and the initial value must be reset before the difference operation for each enumerated value. The initial value is shown in Table 2 .

(1) Calculation of the Opening Time of the One-Way Valve. At the initial moment, the fuel pressure in the high-pressure tubing is $100 \mathrm{MPa}$. In order to keep the fuel pressure stable at around $100 \mathrm{MPa}$, it is necessary to make the inlet and outlet of fuel reach a relative balance. In addition, the fluctuation range of the fuel pressure needs to be smaller. We get the fluctuation of fuel pressure under the opening time of each enumerated one-way valve through the variance. Since the fuel pressure should be stabilized at about $100 \mathrm{MPa}$, the mean value of fuel pressure can be set to $100 \mathrm{MPa}$ for variance calculation. We set the total number of steps calculated by the difference equation to 100,000 , that is, $1 \mathrm{~s}$, and use the MATLAB program to solve the problem. Then, we get the minimum variance $\left(s^{2}=0.8495992\right)$ when the opening time of the one-way valve $\left(\mathrm{t}_{\mathrm{s}}\right)$ is $0.30 \mathrm{~ms}$. Therefore, each time the one-way valve is opened for $0.30 \mathrm{~ms}$, the fuel pressure in the high-pressure tubing can be stabilized at about $100 \mathrm{MPa}$ with small fluctuation.

(2) Adjustment for Opening Time of One-Way Valve. In the rising time of about $2 \mathrm{~s}, 5 \mathrm{~s}$, and $10 \mathrm{~s}$, we will study how to adjust the opening time of the one-way valve to stabilize the final fuel pressure at $150 \mathrm{MPa}$. This problem can be solved by following the program framework of the previous program through modifying the total steps of the differential calculation, screening the final value of fuel pressure closest to $150 \mathrm{MPa}$, and recording the corresponding opening time $\left(\mathrm{t}_{\mathrm{s}}\right)$ of the one-way valve.

Under the rising duration of 2 s, 5 s, and $10 \mathrm{~s}$, the opening duration of the one-way valve with the final fuel pressure closest to $150 \mathrm{MPa}$ is shown in Table 3 .

From the above table, we can observe that when the opening time of the one-way valve is $0.70 \mathrm{~ms}$ and when the running time is greater than $5 \mathrm{~s}$, the fuel pressure is stabilized at around $150 \mathrm{MPa}$. In order to verify this statement, we have carried out the corresponding extended calculations. The calculation results are shown in Table 4 .

According to the tables, when the opening time of the one-way valve $\left(t_{s}\right)$ is $0.70 \mathrm{~ms}$, the time in which the fuel pressure rises from $100 \mathrm{MPa}$ to $150 \mathrm{MPa}$ will be $5 \mathrm{~s}$, and the fuel pressure remains stable at around $150 \mathrm{MPa}$, so the above statement is verified. To stabilize the fuel pressure at $150 \mathrm{MPa}$, we can control the opening time of the one-way valve at $0.70 \mathrm{~ms}$.

For the rising time of $2 \mathrm{~s}$, we can control the opening time of the one-way valve in different sections. We make the opening time in the rising stage $\left(t_{s 1}\right)$ at $0.88 \mathrm{~ms}$ and make the opening time $\left(t_{s 2}\right)$ at $0.70 \mathrm{~ms}$ after $2 \mathrm{~s}$. For the situation of rising time which is at $5 \mathrm{~s}$ and $10 \mathrm{~s}$, we need to make $t_{s}$ at $0.70 \mathrm{~ms}$ to stabilize the fuel pressure at around $150 \mathrm{MPa}$ after the rising time.

\subsection{Establishment and Solution of the Second Model}

2.2.1. Theoretical Analysis and Research Ideas of the Second Model. In the process of practical work, the fuel of A comes from the plunger cavity exit of the high-pressure fuel pump. The fuel injection is controlled by the nozzle's needle valve, so the influence of the high-pressure fuel pump should be considered in the second model. As is shown in Figure 3, we get the angular velocity of the cam and as far as possible make the pressure inside the high-pressure tubing stable at around $100 \mathrm{MPa}$ according to the injector work frequency, high-pressure pipe size, and initial pressure of the first model.

The pressure in the high-pressure tubing varies with time, and the numerical changes of some parameters in the tubing at a certain time will affect the pressure calculation of the high-pressure tubing at the next time. After the discretization of time, the difference equation can be 
TABLE 2: Initial values of partial physical parameters.

\begin{tabular}{lccc}
\hline Parameter & The initial value & Parameter & The initial value \\
\hline$\rho_{0}$ (in-tube fuel density) & 0.85 & $E_{0}$ (elastic modulus of fuel in pipe) & 2171.4 \\
$P_{0}$ (in-line fuel pressure) & 100 & $Q_{0}$ (one-way valve fuel flow) & 15.358 \\
\hline
\end{tabular}

Table 3: Optimal opening time of one-way valve under the rising time of $2 \mathrm{~s}, 5 \mathrm{~s}$, and $10 \mathrm{~s}$.

\begin{tabular}{lccc}
\hline Rise time/s & 2 & 5 & \\
\hline One-way valve opening time $/ \mathrm{ms}$ & 0.88 & 0.70 & 10 \\
Final value of fuel pressure $/ \mathrm{MPa}$ & 150.52 & 149.93 & 0.70 \\
\hline
\end{tabular}

TABLE 4: Optimal opening time of one-way valve under different rising times.

\begin{tabular}{|c|c|c|c|c|c|c|c|}
\hline Rise time/s & 3 & 4 & 7 & 9 & 12 & 15 & 20 \\
\hline One-way valve opening time/ms & 0.76 & 0.71 & 0.70 & 0.70 & 0.70 & 0.70 & 0.70 \\
\hline Final value of fuel pressure/MPa & 150.05 & 150.04 & 150.10 & 150.17 & 150.02 & 149.90 & 150.19 \\
\hline
\end{tabular}

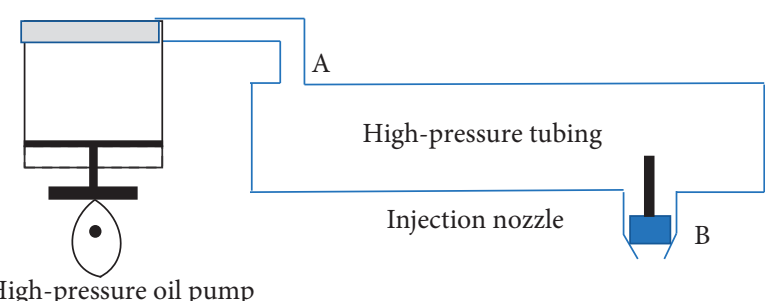

Figure 3: The schematic diagram of the second model.

established to calculate the pressure change of the highpressure tubing.

For the high-pressure fuel pump, it is necessary to solve the length of the polar radius when the one-way valve is opened in the high-pressure fuel pump and determine the polar angle when the one-way valve is opened. In the difference equation, the polar angle is taken as a reference to determine whether the one-way valve is open or not.

Under the condition that the difference equation which reflects the relationship between pressure and time is given, the enumeration method will be used in the second model. The one-way valve's open time that starts from 0 to $0.01 \mathrm{~ms}$ is taken as a step. It will be substituted into the corresponding difference equation to calculate the high-pressure tubing pressure changes. In addition, every speed under the total variance will be recorded. The angular velocity with the minimum of the variance is chosen as the final optimal solution.

In addition, the data shows the movement rule of the needle valve of the nozzle. However, the height of the needle valve is different, and the corresponding amount of fuel injection will be different. Therefore, it is necessary to establish the physical model of the nozzle and establish the function relation between the height of the needle valve and the injection amount of the nozzle. After that, we need to deduce the fuel injection amount of the nozzle within each discrete time interval through the integral principle.

\subsubsection{Establishment of the Second Model}

(1) Derivation for the Injection Volume of the High-Pressure Fuel Pump. For the convenience of research, in this model, the length from the cam axis to the bottom of the plunger of the high-pressure fuel pump is approximately the polar radius. When the cam rotates in the situation in which pressure is $0.5 \mathrm{MPa}$, the movement distance of the plunger of the high-pressure fuel pump $\left(\mathrm{h}_{1}\right)$ is

$$
h_{1}=d_{\max }-d_{\text {min }} .
$$

In this formula, $d_{\max }$ is the maximum value of the polar radius and $d_{\min }$ is the minimum value of the polar radius.

Furthermore, the volume of the plunger chamber $\left(V_{A}\right)$ is

$$
V_{A}=S_{A} * h_{1}+V_{A 1},
$$

where $S_{A}$ represents the bottom area of the plunger chamber of the high-pressure fuel pump and $V_{A 1}$ represents the residual volume of the plunger chamber.

The mass of fuel in the plunger chamber of the highpressure fuel pump $\left(m_{A}\right)$ is

$$
m_{A}=V_{A} * \rho_{0.5} \text {. }
$$

When the pressure inside the high-pressure fuel pump reaches $100 \mathrm{MPa}$, the one-way valve connected with the plunger cavity and the high-pressure fuel pipe opens, and the volume of the fuel at $100 \mathrm{MPa}$ is

$$
V_{A 100 M P a}=\frac{m_{A}}{\rho_{100}} \text {. }
$$

As shown in Figure 4, the polar radius when the one-way valve is opened $\left(d_{o}\right)$ is

$$
d_{o}=d_{\min }+h_{1}-\frac{\left(V_{A 100 M P a}-V_{A 1}\right)}{S_{A}} .
$$

Furthermore, it can be determined that the value of the polar angle $(\theta)$ when the one-way valve is opened is 3.65 according to the given data and $d_{o}$. 


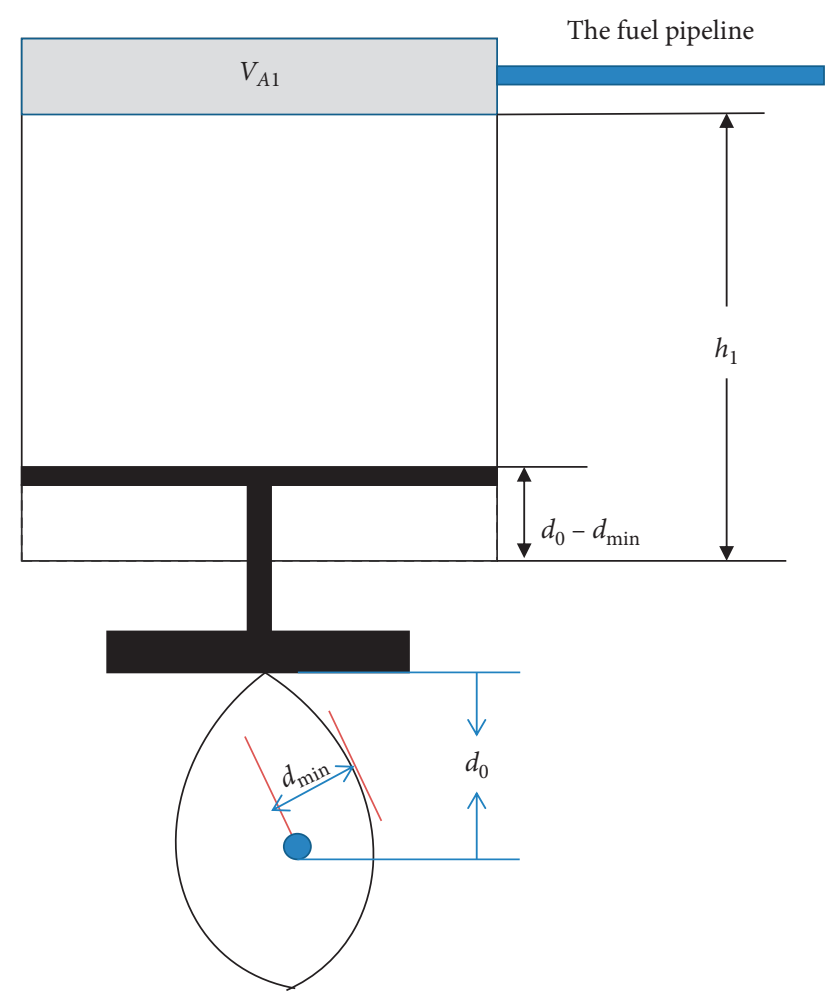

FIgURE 4: Schematic diagram of the high-pressure fuel pump.

The injection volume of the high-pressure fuel pump within each discrete time interval is

$$
\Delta V_{2}=\left\{\begin{array}{l}
\Delta d \cdot S_{A}, \quad \theta \leq 3.65, \\
0, \quad \theta>3.65
\end{array}\right.
$$

where $\Delta V_{2}$ is the volume variation of fuel within the discrete time interval, and $\Delta d$ is the change in the polar diameter within the discrete time interval.

(2) Derivation for Volume of Fuel Ejected from the Needle Valve. According to the given data, the needle valve rises from $t=0 \mathrm{~s}$ to $t=0.45 \mathrm{~s}$, stays still from $0.45 \mathrm{~s}$ to $2 \mathrm{~s}$, and gradually drops from $2 \mathrm{~s}$ to $2.45 \mathrm{~s}$ until the nozzle is closed. The flow of the nozzle is related to the rising height of the needle valve, so the equivalent nozzle area $\left(\mu_{c} f_{c}\right)$ [2] is introduced here, and the calculation formula is as follows:

$$
\mu_{c} f_{c}=\frac{1}{\sqrt{1 /\left(\mu_{z} f_{z}\right)^{2}+1 /\left(\mu_{n} f\right)_{n}^{2}}} .
$$

In the formula, the flow coefficient $\mu_{c}=\mu_{z}=\mu_{n}=C$ $=0.85, f_{n}$ is the area of the bottom-end jet hole, and $f_{z}$ represents the flow area at the surface of the needle valve seat, that is, the side area of the circular table with $r$ as the upper base radius and $R$ as the lower base radius in Figure 5. It can be deduced that when the rising distance of the needle valve is $h$, the flow area is

$$
f_{z}=\sin 9^{\circ} *\left(5+h * \sin 18^{\circ}\right) * \pi * \frac{h}{2}
$$

The flow rate of the jet hole is

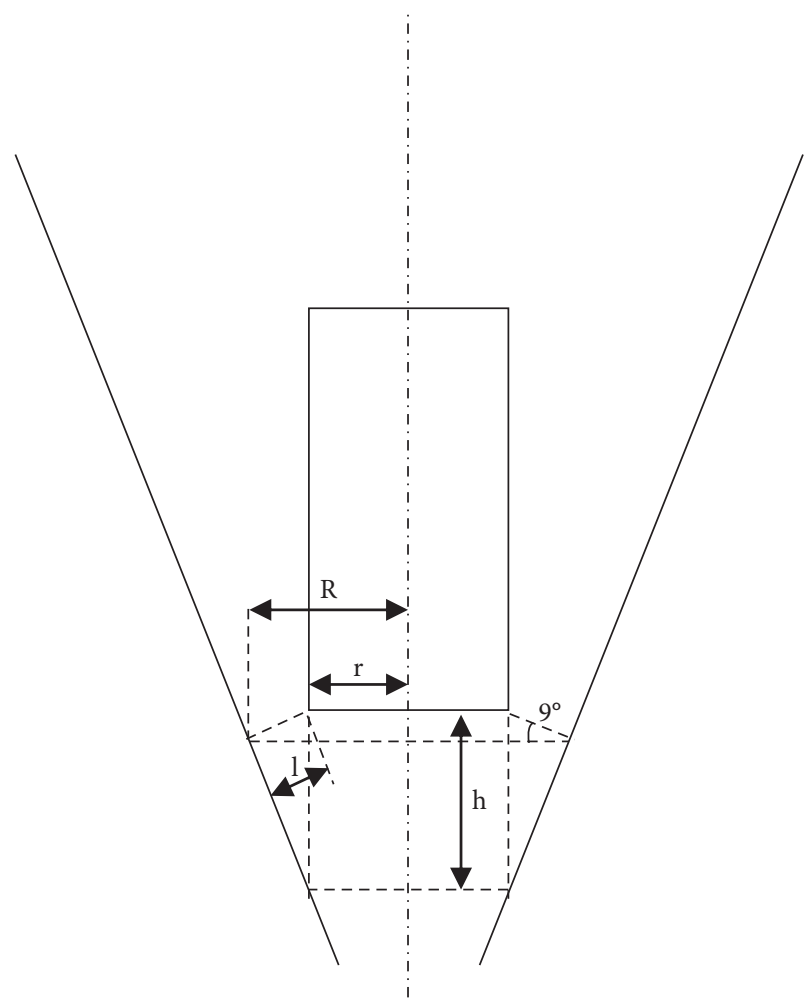

Figure 5: Schematic diagram of the nozzle structure.

$$
Q=C \sin 9^{\circ} *\left(5+h * \sin 18^{\circ}\right) \frac{\pi}{2} * h * \sqrt{\frac{2 \Delta P}{\rho}}
$$

And the injection amount of the nozzle within each time interval is

$$
V_{1}=\left(Q_{n-1}+Q_{n}\right) * \frac{t_{i}}{2}
$$

According to the integration principle, the volume of fuel ejected from the needle valve in one lifting cycle $(V)$ is

$$
V=\sum_{i=1}^{246}\left(Q_{n-1}+Q_{n}\right) * \frac{t_{i}}{2}, \quad\left(t_{i}=0.01 \mathrm{~ms}\right)
$$

(3) Establishment of the Difference Equation. According to the $\Delta V_{1}$ and $\Delta V_{2}$ got from equations (22) and (18), the mass variation of fuel in the high-pressure fuel pipe $\left(\Delta m_{n}\right)$ can be calculated. The variation of fuel density in the high-pressure fuel pipe $\left(\Delta \rho_{n}\right)$ can be calculated with $\Delta m_{n}$. Therefore, the pressure variation of fuel in the high-pressure fuel pipe $\left(\Delta P_{n}\right)$ can be calculated. The specific formula is as follows:

$$
\begin{aligned}
& \Delta m_{n}=\Delta V_{2} \cdot \rho_{100}-\Delta V_{1} \cdot \rho_{n-1}, \\
& \Delta \rho_{n}=\frac{\Delta m_{n}}{V} . \\
& \Delta P_{n}=0.021714 \cdot \frac{\Delta \rho_{n}}{\rho_{n-1}} .
\end{aligned}
$$


According to equations (24), (25), and (26), the changes in each parameter of the high-pressure fuel pipeline are calculated to update the density $\left(\rho_{n}\right)$, pressure $\left(P_{n}\right)$, and running time $\left(t_{n+1}\right)$ of the fuel in the high-pressure fuel pipeline. The formulas are as follows:

$$
\left\{\begin{array}{l}
\rho_{n}=\rho_{n-1}+\Delta \rho_{n}, \\
P_{n}=P_{n-1}+\Delta P_{n}, \\
t_{n+1}=t_{n}+\Delta t_{i} .
\end{array}\right.
$$

Substitute the value of $\rho_{n}, P_{n}$, and $t_{n+1}$ into $\rho_{n-1}, P_{n-1}$, and $t_{n}$ and return to formula (24) to start the loop computation.

\subsubsection{The Calculation and Analysis of Cam Angular Velocity.} Firstly, the cam polar radius $(d)$ and polar angle $(\theta)$ data provided in the data are regressed and fitted with MATLAB software to obtain the relationship between them:

$$
d=0.02279 * \theta^{4}-0.806 * \theta^{3}+8.338 * \theta^{2}-31.955 * \theta+43.56 \text {. }
$$

Then, a program based on the difference equation principle is written in MATLAB. The time of cam rotation of $1 \mathrm{rad}$ is enumerated, and the interval is $0.01 \mathrm{~ms}$ for iterative analysis. The program uses the variance to get the fluctuation of fuel pressure for each enumerated one-way valve opening time. The mean value of fuel pressure is $100 \mathrm{MPa}$ for variance calculation, and the total variance under each rotation speed is recorded during the cycle. Finally, the angular velocity with the minimum total variance is selected as the optimal solution.

According to the analysis mentioned above, the results are as follows:

(1) According to the physical model of the high-pressure fuel pump, $d_{o}$ is $2.7133 \mathrm{~mm}$. According to the known data, when the polar angle of the cam is greater than $3.65 \mathrm{rad}$, the one-way valve will open.

(2) Using the principle of integration, as shown in Figure 6, the fuel injection amount $(V)$ at different time periods whose time interval is $t_{i}$ is calculated.

(3) Using the MATLAB program based on the principle of the difference equation, we can get that the time of cam rotating for $1 \mathrm{rad}$ is $45 \mathrm{~ms}$. The iterative cumulative variance is the smallest at the situation, and the optimal solution of cam speed is $22.22 \mathrm{rad} / \mathrm{s}$.

The variation law of fuel injection quantity of the nozzle model constructed in this model is consistent with the practical work of the nozzle, indicating that the solution results are in accordance with the facts. According to formula (14), the volume of fuel discharged by a highpressure pump at one time $\left(V_{\text {in }}\right)$ is $89.86322 \mathrm{~mm}^{3}$, while the volume of fuel discharged by a single nozzle at one time $\left(V_{\text {out }}\right)$ is $32.533 \mathrm{~mm}^{3}$. If the fuel pressure in the highpressure fuel tube remains unchanged, the speed of the cam is

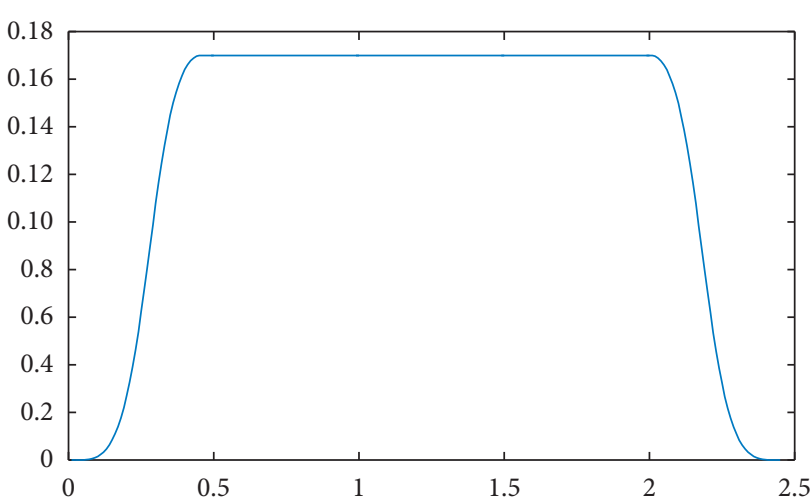

Figure 6: The amount of fuel injection at different time periods of the nozzle.

$$
\omega=\frac{2 \pi}{\left(0.1 * \mathrm{~V}_{\text {in }} / \mathrm{V}_{\text {out }}\right)} \approx 22.75 \text {. }
$$

The cam speed obtained is close to the optimal solution of the program, indicating that the solution results are in accordance with the facts.

\subsection{Establishment and Solution of the Third Model}

2.3.1. System Principle and Research Idea of the Third Model. As is shown in Figure 7, the third model adds a fuel injector and a one-way pressure reducing valve on the basis of the second model. The outlet of one-way pressure reducing valve is a circle with a diameter of $1.4 \mathrm{~mm}$. After opening the oneway pressure reducing valve, the pressure decreases. The two injection nozzles of the high-pressure tubing spew fuel according to the same rule, and the pressure fluctuation of the high-pressure tubing caused by different time intervals of fuel injection of the two nozzles $\left(t_{d}\right)$ is also different. The maximum time interval of fuel injection of the two nozzles is $50 \mathrm{~ms}$. Therefore, the enumeration method is used to traverse the cam rotation speed of the high-pressure fuel pump within the time range of 1-30 ms/rad and the time interval of the two injection nozzles within the time range of 1-50 ms. The variance of fuel pressure is used as the basis for choosing the best combination of cam rotation speed and nozzle's working time interval.

In order to more quickly and effectively control the fuel pressure in the high-pressure tubing, we make the highpressure fuel pump cam rotation cycle, the pressure relief valve working cycle, and the nozzle working cycle consistent; that is, the rotation speed is $100 \mathrm{~ms} / r$. Besides, the entry and ejection of fuel begin and end at the same time. Then, the difference between the total fuel inlet amount and the total injection amount within $100 \mathrm{~ms}$ is solved, and the time needed for the pressure relief valve to work in a cycle is calculated based on the difference value. Since the final pressure is required at $100 \mathrm{MPa}$, we can calculate the fuel pressure at the start of the second injector when the final fuel pressure is $100 \mathrm{MPa}$ and use the fuel pressure as the standard to judge the start time of the relief valve. 


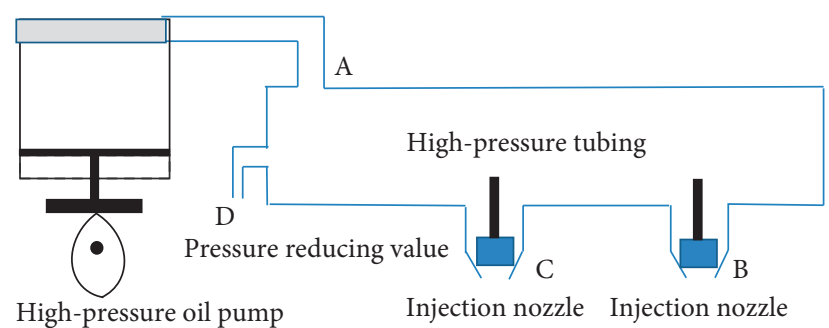

FIgURE 7: The schematic diagram of the third model.

The calculation method of the third model can be obtained by the corresponding transformation on the basis of the second model. First of all, the formula for calculating the fuel injection amount of the two injectors is supplemented. The formula for calculating the fuel injection amount of the first injector is consistent with that in the second model. The fuel injection time of the second nozzle is delayed for the fuel injection amount of the first nozzle, and the delay time is defined as $t_{d}$. The formula is as follows:

$$
\Delta m_{0}=\left(Q_{2 n}+Q_{2 n-1}\right) \cdot \Delta t_{i} \cdot \frac{\rho_{100}}{2} .
$$

In the formula, $Q_{2 n}$ is the fuel injection amount of the second nozzle at time $n$.

In the second model, since the high-pressure fuel pump only works in the rising process of $3.65 \sim 6.27 \mathrm{rad}$, we can calculate the fuel pumping time of the high-pressure fuel pump to be $41.72 \mathrm{~ms}$ according to the proportion and also obtain that the time interval for the two injectors to start working $\left(t_{d}\right)$ is $39.27 \mathrm{~ms}$. In the establishment of the calculation model, the time interval for the two injectors to start working is set as $39.27 \mathrm{~ms}$, the working cycle of the highpressure fuel pump is set as $100 \mathrm{~ms}$, and the calculated step of the difference equation is set as 10000 ; that is, each step's time was $0.01 \mathrm{~ms}$. The difference equation was the same as the second model.

\subsubsection{Calculation and Result Analysis for the Third Model}

(1) The algorithm on the Condition of Two Fuel Injectors. The algorithm steps are as follows:

(1) Double enumeration method is used in MATLAB to traverse $T$ and $t_{d}$ with steps of $1 \mathrm{~ms}$ and $0.01 \mathrm{~ms}$ and to solve the fuel pressure fluctuation's sum of variance in the circulation time ( $1 \mathrm{~s}, 5 \mathrm{~s}$, and $10 \mathrm{~s})$ of the high-pressure tubing at each step.

(2) Select $T$ and $t_{d}$ whose corresponding sum of variance is the smallest.

(3) The angular velocity of cam rotation can be calculated according to the results $\left(t_{d}\right)$ obtained in (2). T is the optimal injection time interval between the two nozzles.

According to the calculation steps, $T$ and $t_{d}$ are calculated when the minimum sum of variance is obtained in $1 \mathrm{~s}$, 5s, and 10s. The results are shown in Table 5.
TABLE 5: Traversal results of different cycle length.

\begin{tabular}{lcc}
\hline System running time $/ \mathrm{s}$ & $\mathrm{T} /(\mathrm{ms} / \mathrm{rad})$ & $t_{d} / \mathrm{ms}$ \\
\hline 1 & 23 & 39 \\
5 & 23 & 50 \\
10 & 23 & 50 \\
\hline
\end{tabular}

When the length of the cycle is $5 \mathrm{~s}$ and $10 \mathrm{~s}$, the calculated $T$ and $t_{d}$ are consistent with the result. It is closer to the state of high-pressure tubing running for a long time when the system running time is set as $5 \mathrm{~s}$ and $10 \mathrm{~s}$. Hence we determine $T$ is $23 \mathrm{~ms} / \mathrm{rad}$ and $t_{d}$ is $50 \mathrm{~ms}$, and the angular velocity of the cam $(\omega)$ is $43.48 \mathrm{rad} / \mathrm{s}$.

When the injection time interval between the two injectors is $50 \mathrm{~ms}$ and the cam angular velocity is $43.48 \mathrm{rad} / \mathrm{s}$, the fuel pressure fluctuation in the high-pressure tube is the least.

(2) Calculation on the Condition of Adding the Pressure Relief Valve. The change of high-pressure tubing fuel pressure that leads to the change of fuel density is small, so we can assume that the pressure of the high-pressure side of reducing valve constant is $100 \mathrm{MPa}$, and fuel density is $0.85 \mathrm{mg} / \mathrm{mm}^{3}$. According to the second model, the external fuel pressure is $0.5 \mathrm{MPa}$, and the flow of pressure reducing valve (Q) is $15.547 \mathrm{~mm}^{3} / \mathrm{ms}$. In a work cycle, the amount of fuel entering the high-pressure tubing $\left(m_{1}\right)$ is $76.383 \mathrm{mg}$, and the amount of fuel injected by a single nozzle $\left(m_{2}\right)$ is $27.653 \mathrm{mg}$. Relying on $m_{1}$ and $m_{2}$, the total mass of fuel discharged from the valve in one working cycle $\left(m_{j}\right)$ is $21.077 \mathrm{mg}$, the reduced pressure value of high-pressure tubing $\left(\Delta P_{j}\right)$ is $1.4568 \mathrm{MPa}$, and the working time of pressure reducing valve in a working cycle $(t)$ is $1.59 \mathrm{~ms}$. According to formula (2), the fuel pressure when the second nozzle starts to work $\left(P_{20}\right)$ is 101.9113 MPa. According to the above parameters and the program of MATLAB, we get the result that the starting time of the pressure reducing valve $\left(t_{j 0}\right)$ is $25.30 \mathrm{~ms}$, and the pressure of the high-pressure tubing $\left(P_{j}\right)$ is $100.6813 \mathrm{MPa}$ when $t$ is $26.89 \mathrm{~ms}$. The result is close to $100 \mathrm{MPa}$.

\section{Conclusion and Discussion}

In this paper, a detailed mathematical model of the highpressure tubing pressure control system is derived. The paper focuses on the precise modeling of the high-pressure fuel pump and needle valve combined with boundary conditions by using difference method. The results show that the model can quickly calculate the best working time of high-pressure fuel pump and needle valve when the accuracy meets the requirements. This model has the following characteristics:

(1) Some geometric parameters of the model are parameterized, which reduces the measurement work and improves the universality.

(2) In the process of establishing the model, we consider the equivalent orifice area of the needle valve and reduce the calculation error of the amount of fuel from the nozzle. 
(3) Compared with the calculation of the differential equation, the difference method is used to solve iteratively, sacrificing the accuracy of the result to some extent, but simplifies the calculation process and greatly improves the calculation speed.

(4) The model with good applicability and versatility is in line with the actual high-pressure fuel pipe system. In addition, it is simple and convenient in specific applications.

(5) When calculating the mass of injected fuel, the default value of the elastic modulus of fuel in the highpressure fuel pipe is a constant independent of the pressure, which causes some calculation errors.

In further research, the relationship between the elastic modulus and the pressure of fuel should be considered, and most of the geometric parameters should be parameterized to further improve the accuracy and generality of the model. For example, if the actual shape of the cam is derived from the relation between the polar radius and the polar angle, and the relation between the length of the cam axis to the bottom of the plunger of the high-pressure fuel pump and the polar diameter is derived, the result will be more accurate. The application of a precise and concise control unit is an important part of reducing the manufacturing cost of the engine fuel delivery system, and it is necessary to improve the market competitiveness of the engine.

\section{Data Availability}

The specific data source of the model is the 2019 Contemporary Undergraduate Mathematical Contest in Modeling. The data used to support the findings of this study are included within the supplementary information files.

\section{Conflicts of Interest}

The authors declare that they have no conflicts of interest.

\section{Supplementary Materials}

The supplementary material files contain the original data used to support the findings of this study and the procedures used for specific calculations for each model. The procedures are all programs that can run on MATLAB. . (Supplementary Materials)

\section{References}

[1] H.-K. Lee, M. F. Russell, and C. S. Bae, "Mathematical model of diesel fuel injection equipment incorporating non-linear fuel injection," Proceedings of the Institution of Mechanical Engineers, Part D: Journal of Automobile Engineering, vol. 216, no. 3, pp. 191-204, 2002.

[2] H. Seungwoo, S. Jaewook, and M. Sunwoo, "Common rail pressure controller for diesel engines using an empirical model," in Proceedings of the IEEE Vehicle Power and Propulsion Conference, IEEE, Seoul, South Korea, pp. 887-892, October 2012.

[3] J. He, B. Wang, A. Zhang, Y. Gong, and L. Yang, "Study on high pressure common rail fuel injection control system of single cylinder diesel engine," Chinese Internal Combustion Engine Engineering, vol. 30, pp. 61-64, 2009.

[4] J. Ling, H. Xie, X. Liu, K. Zhao, and K. Song, "Design and experimental validation of a model-based rail pressure controller for common rail diesel engines," in Proceedings of the 54th Annual Conference of the Society of Instrument and Control Engineers of Japan, (IEEE), Hangzhou, China, pp. 752-758, July 2015.

[5] A. di Gaeta, U. Montanaro, G. Fiengo, A. Palladino, and V. Giglio, "A model-based gain scheduling approach for controlling the common-rail system for GDI engines," International Journal of Control, vol. 85, no. 4, pp. 419-436, 2012.

[6] P. Lino, B. Maione, and A. Rizzo, "Nonlinear modelling and control of a common rail injection system for diesel engines," Applied Mathematical Modelling, vol. 31, no. 9, pp. 1770-1784, 2007.

[7] X. Wang, B. Zhou, and Z. Hou, Mathematical Software and Mathematical Experiments, Science Press, Beijing, China, 2015.

[8] Y. Cui, K. Sun, and Z. Liu, "The measurement of volume elastic modulus of hydraulic oil," Hydraulic Pneumatics and Seals, vol. 17-19, no. 32, 2012.

[9] P. Lino, B. Maione, and A. Rizzo, "A control-oriented model of a Common Rail injection system for diesel engines," in Proceedings of the 10th IEEE International Conference on Emerging Technologies and Factory Automation, vol. 7, September 2005. 